\title{
Diagnosticando Patologias Monetárias: Seus Impactos sobre a Atividade Produtiva na Visão de Keynes e Veblen ${ }^{\star}$
}

\author{
- FERNANDA CARDOSO*
}

- Gilberto TADEu Lima**

\begin{abstract}
RESUMO
Este artigo, elaborado a partir da concepção de patologias monetárias de Keynes, focaliza a dimensão psicológica das relações monetárias - o amor pelo dinheiro e o fazer dinheiro - e seus efeitos sobre o processo produtivo e o bem-estar social. Na tentativa de um embasamento analítico-teórico mais elaborado dessa concepção, além de nos basearmos no próprio Keynes, nos apoiamos na obra de Thorstein Veblen, buscando sugerir respostas tentativas a uma pergunta intrigante suscitada pelo ensaio "As possibilidades econômicas de nossos netos", publicado por Keynes em 1930: por que e como ocorreria a mudança de valores por ele antevista, fazendo com que as pessoas reconheçam o amor pelo dinheiro pelo o que ele realmente é - uma patologia - e se voltem para a verdadeira arte de viver?
\end{abstract}

\section{Palavras-CHAVE}

moral, ética, patologia monetária, atividade produtiva

\section{ABSTRACT}

This paper, which draws upon Keynes' conception of monetary pathologies, focuses on the psychological dimension of monetary relations - money-loving and money-making - and their impacts on the production process and social well-being. In an attempt to provide a more elaborated analytical and theoretical foundation to such conception, we also draw upon some of Veblen's writings, with a view to suggest some tentative answers to an intriguing question one may raise upon reading Keynes' 1930 essay "The economic possibilities for our grandchildren": why - and how - would come about a change of values such as the one envisaged by Keynes, which would lead people to assess the money-motive at its true value, as a pathology, and to devote major attention to the true art of good life?

\section{KEY WORDS}

moral, ethics, monetary pathology, production activity

\section{JEL Classification}

$B|9, B| 5, B 4 I$

\footnotetext{
+ Cabem agradecimentos - acompanhados das isenções de praxe - a um parecerista anônimo e a Antonio Carlos Macedo e Silva por valiosos comentários e sugestões.

* Graduada em Economia pela FEA-USP e Mestranda em Economia no IE-UFR]. [fgcl3@uol.com.br]

* Professor do Departamento de Economia da FEA-USP agradece o suporte de pesquisa do CNPq. [giltadeu@usp. br]

(Recebido em maio de 2005. Aceito para publicação em janeiro de 2006).
} 
There are valuable human activities which require the motive of money-making and the environment of private wealth-ownership for their full fruition. Moreover, dangerous human proclivities can be canalised into comparatively harmless channels by the existence of opportunities for money-making and private wealth, which, if they cannot be satisfied in this way, may find their outlet in cruelty, the reckless pursuit of personal power and authority, and other forms of self-aggrandizement...But it is not necessary for the stimulation of these activities and the satisfaction of these proclivities that the game should be played for such high stakes as at present. Much lower stakes will serve the purpose equally well, as soon as the players are accustomed to them.

J. M. Keynes (CW, VII, p. 374)

\section{INTRODUÇÃO}

A abordagem econômica clássica, e seu desdobramento neoclássico, atribuem à moeda um caráter essencialmente neutro, restringindo o seu papel ao cumprimento das funções de meio de troca e unidade de conta. No entanto, como bem advertiu Keynes no século passado, a moeda não é neutra, pois o seu alto prêmio de liquidez lhe confere atributos que implicam a sua não neutralidade. Como bem explicitado na Teoria Geral (1936), a possibilidade de que a preferência pela liquidez gere uma insuficiência de demanda efetiva faz com que o pleno emprego de fatores não seja o único equilíbrio possível, se é que é realmente atingível sob a existência das tais patologias monetárias. Como bem sugeriu Keynes em seu famoso artigo de 1937, escrito em resposta a críticos da Teoria Geral, se a moeda fosse realmente neutra, quem fora de um hospício desejaria mantê-la como reserva de valor?

O presente artigo, construído a partir dessa intuição fundamental de Keynes, pretende enfatizar a dimensão psicológica das relações monetárias, quais sejam, emprestando os próprios termos de Keynes, o amor pelo dinheiro e o fazer dinheiro. Afinal, essas chamadas patologias monetárias têm conseqüências importantes para a dinâmica do processo produtivo e, simultaneamente, para o bem-estar da sociedade.

Baseando-se não no conhecido Keynes da Teoria Geral, e sim no Keynes com importantes abordagens filosóficas acerca da economia como uma ciência moral a serviço da ética, discutir-se-á a perspectiva otimista de Keynes em relação ao futuro da humanidade. Em um de seus artigos mais conhecidos, "As possibilidades econômicas de nossos netos" (1930), Keynes sugere que quando o problema econômico for resolvido, a sociedade encarará as relações monetárias como o que elas realmente são, ou seja, patologias. A partir de então, as pessoas voltar-se-ão para as coisas belas da vida, exercendo a verdadeira arte de viver. Mas, como e por que ocorrerá essa mudança de valores, essa verdadeira mudança de mentalidade? 
Na tentativa de um embasamento analítico-teórico mais elaborado dessa intuição de Keynes, buscamos apoio na obra do velho institucionalista Thorstein Bunde Veblen, pensador da passagem do século XIX para o XX. Mas este recurso a Veblen é bastante seletivo, pois não pretendemos realizar uma fusão das idéias desses autores, que inclusive apresentam diversos pontos de divergência. Veblen possui uma abordagem antropológico-evolucionária com princípios predominantemente darwinistas, que faz sugestões bastante interessantes acerca da origem das patologias monetárias. $\mathrm{Na}$ sua Teoria da Classe Ociosa, cuja data original de publicação é 1899, Veblen faz uma importante digressão à transição do modo de vida pacífico para o modo de vida predatório, à qual atribui a origem da chamada classe ociosa.

Veblen considera como inerente à natureza humana o instinto do artesanato. Mas, como bem enfatiza o autor, onde quer que exista a instituição da propriedade privada se observa uma luta pela posse de bens, cuja força motivadora é a chamada emulação pecuniária. No entanto, a mais forte das demandas secundárias da emulação é a abstenção do trabalho, pois a desnecessidade de trabalhar passa a ser vista como um requisito de decência, de posição social. Apresentadas as origens, observar-se-á, com o desenvolvimento da indústria, o conflito entre o interesse industrial - produtivo - e o interesse pecuniário - emulativo.

Dado o seu propósito, o restante do artigo está estruturado em três itens. O primeiro apresentará as principais concepções filosóficas de Keynes acerca das patologias monetárias e do futuro da humanidade, baseando-se no próprio autor - e, enfatizando novamente, o foco do presente artigo não é a Teoria Geral - e em importantes comentadores de sua obra. O segundo item, por sua vez, abordará as sugestões evolucionárias de Veblen, tendo como mote a intuição de Keynes apontada no início desta introdução. E, finalmente, o último item sugerirá possíveis respostas tentativas àquelas perguntas que desdobram da intuição de Keynes, baseando-se nas idéias desses dois autores acerca das conseqüências do amor essencialmente patológico pelo dinheiro sobre o processo produtivo. De fato, as críticas que Keynes e Veblen dirigem à teoria neoclássica, especialmente no que diz respeito às relaçôes monetárias, fornecem pistas bastante interessantes sobre quais são as suas conseqüências reais para o desenvolvimento material e ético da sociedade.

\section{A ABORDAGEM DE KEYNES}

Keynes (1930) não descarta a funcionalidade, mesmo que temporária, do amor pelo dinheiro na promoção de well-beingl para a sociedade. A funcionalidade do amor

1 No sentido de bem-estar. Para que não haja confusão com outras acepções desse termo em economia, o mesmo será muitas vezes mantido sem tradução ao longo do artigo. 
pelo dinheiro decorre do estímulo que dirige à acumulação, permitindo assim que o problema econômico fundamental, o da sobrevivência em bases satisfatórias, seja resolvido. Partindo de uma concepção bastante otimista da natureza humana, o autor acredita que uma vez que o problema econômico seja resolvido, os homens passarão a encarar o amor pelo dinheiro como ele essencialmente é: uma patologia. A partir de então os homens voltar-se-iam para a prática da arte de viver, buscando contemplar coisas belas e agradáveis, elevando o seu estado da mente e de espírito. Assim sendo, no presente item discorremos sobre as principais idéias do Keynes com importantes abordagens filosóficas acerca da economia como uma ciência moral a serviço da ética, apresentando as origens de suas idéias e as suas principais inferências.

\subsection{A Origem de Algumas das Concepçóes Filosóficas de Keynes}

A concepção de Keynes de que a Economia é uma ciência moral parece encontrar explicação em seu legado filosófico, formado a partir de suas primeiras reflexões sobre a obra do filósofo moral G. E. Moore. Keynes chegou a Cambridge em 1902 e logo ficou sob a influência de Moore, cujo livro Principia Ethica seria publicado em 1903. Aquelas reflexões que particularmente interessam, pois se relacionam com o entendimento último de Keynes sobre a Economia, são sobre a introspecção, julgamentos individuais de valor e a interdependência orgânica. Sobre este ponto, Davis observa que:

"What Keynes principally inherited from Moore, in fact, was the view that one could intuit, or grasp, in an act of individual judgment, general a priori relationships. This had been the central doctrine of Principia Ethica, where Moore had advanced the view that the good was sui generis and could only be grasped in and of itself." (1991a, p. 92).

Conceitos e pressuposições que parecem ser enganosamente simples são na verdade complexos, de acordo com o método de Moore. Um verdadeiro filósofo deveria fazer perguntas precisas, fazer distinções se necessário e analisar cada termo exaustivamente. Segundo Mini, " $[M]$ oore philosophical priorities are reversed. The method is more important than the conclusion. And if, as is often the case, a devotion to method leads to no firm conclusion, no matter. One will at least avoided useless arguments.” (1991, p. 71). $\mathrm{O}$ autor argumenta que é fácil ver como Keynes se apropriou do método de Moore. Enquanto os predecessores de Keynes permaneceram encantados pela arquitetônica imponente da teoria clássica, Keynes examinou os seus componentes básicos. Longe de ter se impressionado, ele considerou tal estrutura ilógica, contraditória e superficial. A economia clássica não configurava uma análise séria, e sim de uma coleção de relaçôes simples obtidas por meio de seu método analógico e retórico. 
Ainda segundo Mini, o grande objetivo do Principia Ethica de Moore era descobrir quais eram os princípios fundamentais da razão ética. ${ }^{2}$ Moore não tinha a ilusão de que a ética era uma ciência: não se podem inferir certezas na ética por causa da ignorância que circunda as consequiências de nossas decisões. Como os efeitos de um ato continuam por um tempo indefinido, nosso conhecimento acerca dos efeitos futuros será extremamente falho, e assim não há como saber quais ações produzem o bem. Se insistirmos em aplicar padróes rígidos para julgar o que é certo ou é errado, estaremos inaptos a decidir sobre qualquer regra de conduta. Mas, por outro lado, se abandonássemos os padrões mais altos e aplicássemos um padrão prático - cotidiano -, a ética poderia fornecer algumas regras. E essas regras são aquelas mais universalmente reconhecidas pelo senso comum.

Moore dizia que a ação prática é tão difícil de avaliar que qualquer tentativa de fazêlo leva à inação, pois os desdobramentos conseqüentes de uma ação são infinitos. Keynes, por sua vez, acreditava que embora seja difícil avaliar o melhor curso de uma ação, é possível exercer julgamento, ou até seguir um compromisso intuitivo. Para O’Donnell (1989), o jovem Keynes acreditava que uma certa ignorância em relação ao futuro não é razão suficiente para negar a possibilidade de um julgamento racional sobre ações. Então, o julgamento racional poderia proceder mesmo em condições de incerteza. ${ }^{3}$ Mas é importante observar que, segundo Mini (1991), o método de Moore ainda mostrou a Keynes que uma análise não tem que levar necessariamente a certezas; tudo o que ela necessita fazer é evitar o erro.

De acordo com Fitzgibbons (1988), o efeito da filosofia de Moore foi negar que qualquer ação em política ou economia poderia ter uma justificação ética. Moore defendia que não há conexão causal entre ética e conduta, porque o compromisso é imposto de fora para dentro e, portanto, está fora da ética. Entretanto, argumenta que Moore não defendeu o cálculo utilitarista como uma forma de conduta já que na prática é impossível, pois nós não podemos calcular as conseqüências num mundo complexo no qual os desdobramentos de nossas ações continuam infinitamente. Como saída, já

2 Mini sugere que o pensamento ético de Moore pode ser resumido da seguinte forma: primeiramente, não há ética científica ou não há nenhuma lista de deveres e virtudes; além disso, muitas leis reconhecidas pelo senso comum podem ser seguidas de maneira profícua, pois podem levar à estabilidade social sem que seja necessário atingir o verdadeiro 'bem'; e, finalmente, nas decisões cotidianas, o indivíduo provavelmente escolherá corretamente se ele tomar decisões com base no senso comum. (1991, p. 80).

3 Uma tentativa recente de refinamento do conceito de incerteza é desenvolvida em Dequech (2004), cuja conclusão básica é que este conceito tem tanto uma dimensão ontológica - posto que está associado a uma visão da realidade - como uma dimensão epistemológica - porquanto está associado com a falta de algum tipo de conhecimento. A nosso juízo, porém, esta dupla dimensionalidade não coloca em xeque a concepção do jovem - e, em verdade, inclusive do maduro - Keynes de que o julgamento racional pode proceder mesmo em condições de incerteza. Em certo sentido e extensão, pode-se mesmo sugerir que a percepção dessa dupla dimensionalidade da noção de incerteza subjaz à concepção de probabilidade de Keynes, na qual probabilidade é uma propriedade da maneira como é pensado o mundo - ou, mais precisamente, é um grau de crença. Vale dizer, o próprio conceito de crença racional de Keynes teria assim, nessa sugestão, tanto uma dimensão epistemológica como uma dimensão ontológica. 
que eliminou a possibilidade de tanto as motivações como as consequiências da ação serem guias de boa conduta, Moore defendeu seguir as convençốes já que, sob sua concepção, todos sabem bem o que é uma boa conduta e, dado que todos seguem convenções, a conformidade com elas é o melhor para a civilização. Em relação às convenções, vale observar que Keynes não descartará a sua funcionalidade. No seu famoso artigo-resposta de 1937, o qual será melhor explorado mais à frente, Keynes explicita que dado que o futuro é incerto, e que é também necessário tomar decisões, para nos conservarmos como homens racionais e econômicos, podemos tomar como guia o presente, o vigente estado de opinião e as chamadas convenções.

Em "My Early Beliefs" (1938), porém, Keynes veio a repudiar algumas de suas concepçóes filosóficas originárias. Keynes explicita que o que o chamado grupo de Bloomsbury, do qual fazia parte, depreendeu de Moore não correspondia ao todo que ele oferecia. ${ }^{4}$ Em suas palavras, "[h]e had one foot on the threshold of the new heaven, but the other foot in Sidgwick and the Benthamite calculus and the general rules of correct behavior." (1938, p. 436). Os membros do grupo de Bloomsbury aceitaram a 'religião' (atitude de alguém em relação a si mesmo e ao fim último) de Moore e descartaram a sua "moralidade" (atitude de alguém em relação ao mundo exterior e ao intermediário). De fato, o que os adeptos de Moore consideravam como uma das maiores vantagens da sua "religião" era que fazia a moral desnecessária.

Mas, insistir em permanecer sob a influência dessa concepção, segundo Keynes (1938), seria austero e platônico, principalmente porque se ignorava a interdependência de qualquer indivíduo com o mundo exterior e porque só se baseava no presente, descartando as conseqüências provocadas por uma ação. Keynes classifica essa concepção como "religião" porque, baseando-se nela, tudo passava a possuir um caráter estritamente racional e científico, ou seja, incontestável. Como o autor explicita em uma passagem, "[o]ur apprehension of good was exactly the same as our apprehension of green, and we purported to handle it with the same logical and analytical technique witch was appropriate to the latter." (1938, p. 438).

Para Keynes (1938), os intelectuais do grupo de Bloomsbury eram o que se poderia dizer como os últimos dos utópicos, pois acreditavam num progresso moral contínuo baseado na crença de que cada raça humana é composta de pessoas decentes e racionais, influenciadas por padrões verdadeiros e objetivos. Mas, como conseqüência do seu "estado geral de espírito", segundo Keynes, os membros do grupo de Bloomsbury não compreenderam a natureza humana, incluindo a deles mesmos. A racionalidade que atribuíram a essa natureza conduziu à superficialidade, não apenas de julgamento, mas também de sentimento. Como apontado por Keynes,

4 Para uma apresentação detalhada sobre o - idiossincrático - grupo de Bloomsbury, sugerimos o excelente Mini (1991). 
"The attribution of rationality to human nature, instead of enriching it, now seems to me to have impoverished it. It ignored certain powerful and valuable springs of feeling. Some of the spontaneous, irrational outbursts of human nature can have a sort value from which our schematism was cut off." (1938, p. 448).

De acordo com Davis (1991b), Keynes objetou a definição de conduta correta de Moore como uma ação que produz consequiências boas. Em particular, Keynes argumentou que o princípio de unidades orgânicas de Moore é insuficiente para uma determinação bem-sucedida do que é bom, pois, na visão de unidades orgânicas de Moore, o compromisso de qualquer indivíduo seria o de buscar a maior goodness do próprio universo. $\mathrm{O}$ autor ainda explicita que, para Keynes, o que faz com que algo em particular seja bom é que a nossa percepção dele inspire sentimentos genuinamente bons em nós; conforme Davis, “...for Keynes goodness does not exist apart from good feelings.”(1991b, p. 66).

Davis (1991b) argumenta ainda que, para Keynes, a goodness possui uma dimensão subjetiva no sentido de que não existe à parte da experiência dos indivíduos, mas, sim, que depende sobremaneira da experiência. Ao mesmo tempo, isto não implicava para Keynes que o que pode ser dito bom ou ruim é inteiramente relativo ao indivíduo. $\mathrm{Na}$ visão de Moore, desde que o ser "bom" é uma simples qualidade existindo absolutamente nela e por ela mesma, o "bom" deve ser reconhecido essencialmente da mesma forma por cada indivíduo, com que não faz sentido falar de "bom" como ele de fato aparece ao indivíduo ou como ele deveria normalmente aparecer ao individuo. Porém, segundo o mesmo Davis, Keynes não estava argumentando que nada na verdade existe à parte de nossa experiência: sua concepção era a de que nossa caracterização do que existe é inescapavelmente dependente de nossa experiência e que é um erro ignorar isso na abordagem sobre a intuição de alguém, assim como fez Moore.

Nesse contexto, vale outra observação: a teoria da conduta de Moore é 'act-consequentalist', da qual segue que não há regra ou compromisso que contenha uma verdade universal. Segundo O’Donnell (1989), a posição de Keynes é similar, mas concede certa importância a regras e compromissos, alguns dos quais poderiam ser obedecidos como se fossem universalmente verdadeiros. Mais especificamente, a verdade teria a vantagem de fornecer uma melhor estabilidade, e enquanto uma verdade superior não fosse estabelecida o caos seria evitado somente por admiti-la. Ainda segundo O’Donnell, Keynes admitia que certas regras e compromissos básicos tinham papéis importantes na facilitação das relações sociais e eram precondições para aumentar o nível de goodness. 


\subsection{A Natureza da Economia, uma Ciência Moral}

Para compreender adequadamente a abordagem de Keynes, ou seja, a de que a Economia é uma ciência moral a serviço da ética, deve-se ter claro que por trás do Keynes economista está um Keynes com importantes concepções filosóficas acerca das conseqüências das relações monetárias sobre o processo produtivo e, conseqüentemente, sobre o bem-estar da sociedade. Só a partir dessa clareza pode-se entender a sua concepção de Economia como uma extensão da ética.

O que é ciência moral? Segundo O’Donnell (1989), enquanto cada ciência lida com um determinado departamento da realidade, todas as ciências são unificadas pela Filosofia. A Ciência, como sinônimo de Filosofia, é dividida em dois departamentos, o das ciências naturais e o das ciências morais. As ciências morais são extensões de conhecimento que lidam com mente e conduta e, por conseguinte, com seres humanos como sujeitos e seres pensantes. As ciências naturais se ocupam da matéria e da vida, ou seja, dos homens como seres inanimados e desprovidos de consciência.

Keynes define a Ciência como "the application of logic and rational analysis to the material presented as sense-data." (CW, X, p. 438). Classifica a Economia, indubitavelmente, como ciência, uma extensão natural da Filosofia, e como moral, distinguindo-a da ciência natural. Nas suas palavras,

"I also want to emphasize strongly the point about economics being a
moral science. I mentioned before that it deals with introspection and
with values. I might have added that it deals with motives, expecta-
tions, and psychological uncertainties. One has to be constantly on guard
against treating the material as constant and homogeneous." (CW, XIV,
p. 300).

Assim, Keynes considera a Economia como uma extensão da lógica, uma forma de pensar que inclui raciocínio indutivo, intuitivo, de senso comum e probabilístico. ${ }^{5}$ A Economia está subordinada àqueles assuntos relacionados a princípios de escolha racional e conduta, ou seja, à Filosofia e à Lógica. Nas palavras do próprio Keynes,

\section{"Economics is a science of thinking in terms of model joined to the art of choosing models which are relevant to the contemporary world. It is com- pelled to be this, because, unlike the typical natural science, the material to which it is applied is, in too many respects, not homogeneous through time (...) as against Robbins, economics is essentially a moral science and}

5 Mas não no sentido de probabilidade numérica, já que esta não pode ser definida dada a impossibilidade de se conhecer todas as informações e muito menos de quantificá-las, mas no sentido de crença racional, conforme adiantado na nota 3 . 
not a natural science. That is to say, it employs introspection and judgments of value." (CW, XIV, p. 296-7).

Keynes argumenta que a Economia é de natureza essencialmente inexata por causa da especificidade de seu objeto de estudo, o comportamento individual, pois ele apresenta grandes dificuldades de mensuração e comparação por ser altamente interdependente com muitos outros fatores como motivações, expectativas e o meio ambiente circundante. Vale lembrar que o indivíduo é também central na análise da teoria neoclássica, entretanto a abordagem é diferente, já que desconsidera os aspectos morais, tornando os indivíduos semelhantes aos átomos das ciências naturais. ${ }^{6}$ Tal idéia está bem explicitada na passagem que se segue:

\section{"It is as though the fall of the apple to the ground depended on the apple's motives, on whether it is worthwhile falling on the ground, and the whether the ground wanted the apple to fall. And on mistaken cal- culations on the part of the apple as how far it was from the center of the earth." (CW, XIV, p. 300).}

Significantes influências recíprocas ocorrem entre o comportamento do indivíduo e a realidade econômica, o que concede à Economia um inevitável elemento de incerteza que permeia muitas de suas definições. Portanto, transpor o método das ciências naturais tem uso limitado em Economia. Basear-se em intuição e julgamento aparece para Keynes como uma alternativa racional, já que acredita que contemplar aspectos morais não torna a ciência "irracional" ou "ilógica". São requeridas mais do que deduções lógicas dos modelos, e aqui se adentra no campo da Economia Política, cheio de incertezas empíricas e onde a seleção e o peso dado a fatos importantes são afetados pelos julgamentos de valor.

A introspecção e o julgamento de valor permitem ao economista estabelecer modelos para o comportamento dos indivíduos. Então, não há como querer estabelecer uma objetividade estrita no exercício da Economia, pois o seu centro de investigação e inclusive quem o investiga são inerentemente mutáveis e complexos. Sobre esse ponto,

6 Keynes, numa interessante passagem contida no seu Essays in Biography, destaca a complexidade do estudo da economia. Cita numa nota de rodapé que o professor Max Planck, o famoso criador da Teoria Quântica, uma vez disse a ele que, quando jovem, pensava em estudar economia, mas desistiu porque lhe parecia muito difícil. Segundo Planck, o amálgama de lógica e intuição e a grande gama de fatos, muitos dos quais não precisos, que eram requeridos para a interpretação econômica eram muito complexos para aqueles que estavam acostumados a trabalhar com as implicações de fatos simples que podiam ser conhecidos com certo grau de precisão. ( $C W, \mathrm{X}, \mathrm{p} .186 \mathrm{n})$. A proximidade entre a abordagem de Keynes e a abordagem dos sistemas complexos, recentemente aplicada à economia, é demonstrada em Cardoso e Lima (2005). Essa abordagem tem como uma idéia central a de que as ações individuais promovem conseqüências não intencionais como resultado de um processo de auto-organização. Keynes já havia explorado essa idéia de conseqüências não intencionais, conforme evidenciado, por exemplo, em sua elaboração do paradoxo da poupança. Para uma introdução à abordagem dos sistemas complexos, vale consultar, por exemplo, Albin (1998) e Gribbin (2005). 
Davis argumenta que "...introspection would enable the economist to ascribe motives to individuals, given their observed behavior; and judgments of value would enable the economist to weigh the strength of individual's commitments to various courses of action they have undertaken." (1991a, p. 94).

Em seu famoso artigo de 1937, Keynes classifica a teoria econômica (neo)clássica como uma técnica bela e polida que tenta lidar com o presente abstraindo o fato de que sabemos muito pouco sobre o futuro. Uma teoria que somente toma o presente como guia para o futuro, crê que o estado vigente de opinião sumaria adequadamente as perspectivas futuras e conforma-se com o comportamento convencional está sujeita a mudanças repentinas e violentas. Segundo ele:

"The orthodox theory assumes that we have a knowledge of the future of
a kind quite different from that which we actually possess. This false ra-
tionalization follows the lines of the Benthamite calculus. The hypothesis
of a calculable future leads to a wrong interpretation of the principles of
behavior which the need for action compels us to adopt, and to an under-
estimation of the concealed factors of utter doubt, precariousness, hope
and fear." (Keynes, 1937, p. 122).

Para Keynes, somente uma forma de conseqüencialismo aberta a uma forma nãonumérica de probabilidade e guiada pelo 'peso do argumento" ${ }^{77}$ e pelo 'risco moral ${ }^{8}$ poderia servir como uma teoria geral do comportamento racional. A impotência do cálculo matemático em algumas situações implica que a razão pode encontrar algumas alternativas e por isso apela para a intuição e para o julgamento direto.

Uma das proposiçôes mais importantes que a Teoria Geral levantou é a de que as virtudes privadas, como a frugalidade, zelo e até mesmo, sob uma perspectiva mais ampla, a busca por lucro, eram vícios públicos. Grande prova disso é o novo enfoque que concede à poupança, enquanto abstenção de consumo, como uma causa do desemprego, na medida em que o seu aumento pode diminuir o nível de demanda efetiva. Assim, o que sob o ponto de vista do indivíduo é uma atitude 'virtuosa', no agregado esse comportamento promove um menor bem-estar geral. Mas vale ressaltar que, como mencionado anteriormente, Keynes acredita que o amor pelo dinheiro tem funcionalidade para a resolução do problema econômico.

7 Trata-se da quantidade de evidência que sustenta o julgamento de probabilidade. Isto não necessariamente altera a probabilidade, mas pode alterar a quantidade de confiança que se tem no julgamento de probabilidade. (Skidelsky, 1992, p. 60).

8 Tal princípio sugere que é mais racional objetivar o 'menos' que parece mais provável do que objetivar o 'mais' que parece menos provável. (Skidelsky, 1992, p. 60). 
No artigo "O fim do laissez-faire" (1926), por sua vez, Keynes aponta como possíveis causas dos males econômicos o risco, a incerteza e a ignorância. As grandes desigualdades de riqueza, o desemprego e as reduções da eficiência e da produção são conseqüências da vantagem situacional ou de aptidóes que uns indivíduos têm sobre os outros. E dado que pode ser do interesse dos próprios indivíduos a perpetuação desses males, a cura para tais parece estar fora da competência dos indivíduos.

Na visão de Fitzgibbons (1988), a ética racional de Keynes é uma ética mais de motivações do que de conseqüências. Além disso, para Carabelli (1991), o método de Keynes não dissocia a teoria da prática. E, por possuir esse caráter prático e ativo, a teoria de Keynes é voltada para as possibilidades de transformação da realidade por meio de mudanças das crenças, opinióes e comportamento.

Mesmo assumindo uma adequada uniformidade da composição orgânica humana, pode-se dizer o que um homem poderia sentir e pensar, mas não o que ele pode sentir e pensar de fato, pois isto sempre depende das experiências que esse indivíduo acumulou. Segundo Davis (1991a), Keynes vê claramente duas dimensões no pensamento de cada indivíduo, uma objetiva e outra subjetiva, já que a base dos nossos graus de crença é parte de nossa formação humana mais no que diz respeito às nossas percepções e memórias do que propriamente à lógica formal.

Segundo Fitzgibbons (1988), Keynes reconstruiu uma filosofia da ética racional, pela qual uma ação racional em relação a si própria, como um meio de vida, divorciada, se necessário, dos frutos da ação, leva à virtude. Sob a abordagem de Keynes, existe uma relação direta entre a ética e a desordem do mundo. Os sentidos de justiça e criatividade são derivados de uma virtude pessoal particular, e muito do que pode parecer lógico pela perspectiva do racionalismo egoísta pode levar a um desastre histórico, guerra ou depressão. Uma ação pode melhorar as possibilidades de alguém sob um ponto de vista egoísta, mas pode resultar numa situação pior quando analisada sob a perspectiva da unidade orgânica, ou seja, da sociedade como um todo. Como os indivíduos fazem parte de uma sociedade, o estado em que essa última se encontra também influencia o estado dos indivíduos.

De acordo com a concepção de Keynes, a Economia Política pode, deve e precisa ser colocada a serviço da construção de uma sociedade racionalmente ética na qual prevalece a goodness. A Economia é um método, uma forma de pensar que ajuda a desenhar conclusóes corretas. Segundo a perspectiva otimista de Keynes, sugerida por seu artigo de 1930, "As possibilidades econômicas de nossos netos", quando a acumulação de riqueza não for mais tão importante do ponto de vista social, ocorrerão vultosas mudanças no código de moralidade que farão com que o problema econômico não 
seja mais superestimado, sendo parte da preocupação apenas de especialistas: os economistas. Em suas próprias palavras,

"[W]e shall be able to afford to dare to assess the money-motive at its true value. The love of money as a possession - as distinguished from the love of money as a means to the enjoyments and realities of life - will be recognized for what it is, a somewhat disgusting morbidity, one of those semi-criminal, semi-pathological propensities which one hands over with a shudder to the specialists in mental disease." (Keynes, CW, IX, p. 329).

A humanidade será capaz de reavaliar o motivo econômico em seu real valor. O amor pelo dinheiro como um fim será então reconhecido como uma patologia. ${ }^{9}$ Em vez de fim em si mesmo, o dinheiro será reconhecido como meio para se fazer da melhor forma a arte de viver. Mas enquanto esse momento não chega, as condutas de avareza, precaução e usura prevalecerão, pois, segundo Keynes, somente elas nos conduzirão à resolução definitiva do problema econômico, o da luta pela subsistência. Diz ele:

"O ritmo em que poderemos atingir esse nosso destino de satisfação econômica será condicionado por quatro fatores - nossa capacidade de controlar a população, nossa determinação em evitar guerras e dissensões civis, nossa disposição em confiar à ciência a direção dessas questôes, que constituem propriamente a preocupação da ciência, e o ritmo de acumulação, fixado pela margem entre a produção e o consumo; este uiltimo facilmente zelará por si depois da ocorrência dos três primeiros." (Keynes, 1930, p. 159).

\subsection{Considerações sobre a Abordagem de Keynes}

Entender a Economia como uma ciência moral implica olhar não apenas para o que é externalizado pelos indivíduos, mas principalmente para sua formação, o que certamente nos remete ao que entendemos por moral, sendo que a nossa maneira de

9 A respeito dessa idéia de amor pelo dinheiro, Bridel e Presley (1997) sugerem que a visão de Keynes sobre a psicologia do especulador se deve em grande parte à influência de um amigo jornalista francês, Marcel Labordère, com quem Keynes se correspondeu durante vários anos. Em uma das cartas que escreveu a Keynes, datada de Setembro de 1928, Labordère assim discorreu sobre o dinheiro: "It is self evident that men will never be able to know what money is no more than he will be able to know what God is [...] Money is not the infinite but is the indefinite, an astounding complex of all sorts of psychological as well as material reactions." (Bridel e Presley, 1997, p. 458). Segundo Skidelsky (1992, p. 122), Carl Melchior, um banqueiro alemão, e Labordère eram os melhores amigos estrangeiros de Keynes. Porém, uma análise cuidadosa dessa interação vê-se prejudicada sobremaneira pelo desaparecimento de quase a totalidade da correspondência de Keynes para Labordère, embora 60 cartas recebidas por Keynes estejam arquivadas na biblioteca do King's College, em Cambridge. 
olhar, e até mesmo aquilo que enxergamos, decorre intrinsecamente da nossa própria moral.

Analisar o papel que a moeda exerce na sociedade é uma boa maneira de dar sentido a esse apelo de Economia como uma ciência moral. Baseando-se somente na observação das ações que envolvem moeda, como a troca, por exemplo, pode-se chegar à mesma conclusão a que chegaram os (neo)clássicos: a moeda é essencialmente neutra, não desempenha nenhum papel além de ser meio de troca e unidade de conta. Simplificando, a moeda não é nada mais do que um instrumento facilitador das relações entre os agentes, assim como uma ponte facilita a chegada entre dois pontos opostos.

Keynes não compartilha da idéia de neutralidade da moeda, exatamente porque a relação que os indivíduos estabelecem com essa entidade não tem somente motivações práticas, mas inclusive psicológicas. ${ }^{10}$ Daí vem a sua conceituação do "amor pelo dinheiro" e do "fazer dinheiro" e, por conseguinte, da preferência pela liquidez, graças à capacidade da moeda de funcionar como uma "máquina do tempo". (Lima, 1992). Pode-se sugerir, portanto, que o amor pelo dinheiro é o que realmente motiva os agentes a preferirem reter moeda em vez de investir em qualquer outro ativo produtivo. Porém, qual o fundamento desse amor pelo dinheiro? Uma resposta bastante sugestiva parece ser a vontade de obter poder e, por conseguinte, a possibilidade de exercer controle sobre os outros indivíduos. Esse poder permitiria ao indivíduo manipular o funcionamento dos elementos que compõem a sua vida da maneira mais conveniente para ele, seja para o bem ou para o mal dos outros indivíduos.

Voltando ao artigo "As possibilidades econômicas de nossos netos", fica claro que o apego ao dinheiro é útil para a resolução do problema econômico, pois promoveria a acumulação necessária para solucioná-lo mais rapidamente. Por outro lado, o que se observa na realidade é um processo de desigualdade cada vez maior entre classes sociais, regiões e países, ou seja, embora a acumulação esteja aumentando, as questões de subsistência para a maioria da população mundial não têm sido satisfeitas. Então, como esse problema econômico poderia ser resolvido, se a necessidade de se sentir seguro ou a vontade de obter poder faz com que os indivíduos queiram acumular para

10 No seu "Tratado da moeda" (CW, Vol. VI, p. 258), Keynes cita Freud que argumenta que há razões peculiares incrustadas em nosso subconsciente pelas quais a moeda, em particular, deveria satisfazer fortes instintos e servir como um símbolo. Por necessidade de delimitação e focalização, o presente artigo não abordará essa conexão freudiana mencionada de passagem, sem elaboração adicional, pelo próprio Keynes. Um tentativa de elaboração dessa conexão é desenvolvida por E. G. Winslow, para quem a ênfase de Keynes "...on the love of money along with the division of the money-motives into the 'moneymaking' and 'money-loving' instincts closely parallels the Freudian description of the anal-sadistic character. Psychoanalysis points to repressed and sublimated anal erotism as the source of this passion. It also provides an interpretation for each of its two aspects. The 'money-making' instinct is the product of repression and sublimation of the interest in intensifying pleasure in anal canal by postponing defecation and allowing fecal matter to 'collect' or 'accumulate' in the canal. The 'money-loving' instinct is the product of repression and sublimation of the interest in excrement itself." (1986, p. 565-6). 
si cada vez mais? Como inverter esse processo, se enquanto o problema econômico não for resolvido os códigos de moralidade não mudarão?

Questiona-se se, desde que os interesses são relativos a diversas possibilidades, é racional que, num futuro qualquer, nós possamos pensar que alcançaremos um estado de goodness? Além disso, não seria ética e moralmente - na acepção do próprio Keynes - ingênuo dizer que nós devemos dar menor espaço para atitudes e motivações que pensamos serem prejudiciais até que nosso problema econômico básico seja resolvido, quando então retomaríamos nosso tradicional código moral e construiríamos um mundo novo e moralmente melhor?

Mesmo com uma instituição central ocupando os espaços não preenchidos pelos indivíduos e, portanto, restringindo de alguma forma a ação deles e as suas consequiências para o estado de goodness, como sugerido por Preston (1987), isso não garante que os objetivos primeiros sejam alcançados, pois os códigos de moralidade continuam os mesmos. Uma solução dada por Preston seria a de imbuir as instituições, que de certa maneira influenciam os indivíduos enquanto cidadãos, de valores como altruísmo e compaixão. Mas como fazer com que essas instituições sejam imbuídas de tais valores? E, mais complexo do que isso, haverá realmente alguma forma de que, mesmo estabelecendo todas as condições que se pressupõe serem necessárias para atingir a goodness, ele será de fato atingido? Fatos encenados por células pensantes, como dito anteriormente, são inerentemente incertos.

Afinal, o próprio Keynes admite que se o mercado, enquanto instituição, é deixado agir por seus próprios mecanismos, ou seja, se os indivíduos agirem por seus próprios interesses, não se atinge um estado de bem-estar geral, como preconizava a teoria (neo)clássica. Então, clamar por considerações morais de certa forma atenuaria os 'buracos' do sistema capitalista, conferindo-lhe maior estabilidade.

Mas, por outro lado, fica claro que Keynes não considera como racional apenas aquele indivíduo que age de maneira egoísta. Pelo contrário, é perfeitamente possível ser racional e levar em consideração aspectos morais e, por conseguinte, o bem-estar dos outros indivíduos. Ou, indo até mais adiante do sugerido por Keynes, "irracional" seria aquele indivíduo que não enxerga o resultado de uma atitude individual sua para o "todo orgânico" - o sistema social - do qual faz parte.

Keynes é bastante enfático no que diz respeito à importância dos estados da mente. Embora não haja como saber se uma ação é boa ou ruim, posto que não há como saber qual será a natureza de suas conseqüências, há, por outro lado, como inferir o que são bons estados da mente. No seu artigo de 1930, o autor prevê uma mudança de mentalidade que fará com que estados da mente mais elevados sejam prevalecentes, 
tornando patente que o amor pelo dinheiro é uma patologia. A filosofia mooreana prega que o que importa são os fins últimos, negligenciando o intermediário. Então, poder-se-ia inferir que a influência de Moore sobre Keynes teria se manifestado igualmente nessa previsão de uma mudança de mentalidade: não importa como ela se dará; o importante é definir os bons estados da mente que se estabelecerão a partir dela. ${ }^{11}$

Como explicitado no item introdutório do artigo, as perguntas fundamentais que o permeiam são as de que como e por que se daria a tal mudança de valores? A nosso ver, Keynes fornece pouco mais do que interessantes impressões intuitivas sobre essas questões. Por conta disso, no próximo item serão apresentadas as principais idéias evolucionárias de Veblen a fim de se buscar pistas que alarguem nosso horizonte de compreensão dessas questões.

\section{A ABORDAGEM VEBLENIANA}

De acordo com Hutton (1999), encontrada no trabalho de Thorstein Veblen e John Commons nos primeiros anos do século XX, a tradição institucionalista tinha, ao menos até o início dos anos 1930, uma considerável influência na academia econômica americana e na política econômica. Na sua visão, é difícil especificar um grupo de hipóteses centrais que definem o - mais recentemente chamado - velho institucionalismo, mas pode ser identificada uma série de características comuns. O velho institucionalismo é holístico e orgânico em sua abordagem, e as crenças, valores e ações dos indivíduos são vistos como culturalmente incrustados. O seu objetivo é descrever as complexidades da organização e o controle da disposição social na sua evolução histórica, e a preocupação central consiste em entender o processo de mudança e de ajustamento institucional. A economia é vista como uma ciência pragmática, evolucionária e política que busca melhorar o funcionamento da organização econômica por meio da mudança institucional.

No tocante aos antecedentes intelectuais de Veblen, uma influência bastante significativa parece ter sido proveniente de John Bates Clark. Embora Clark fosse um autor neoclássico, tendo mesmo sido um dos elaboradores da concepção de que a distribuição da renda é determinada pela contribuição relativa dos fatores de produção, e Veblen um institucionalista evolucionário, Stabile (1997) chama a atenção para o fato de que a abordagem marginalista que Veblen tanto criticou não era exatamente

11 Embora o enfoque do presente artigo não seja o Keynes enquanto formulador e proponente de políticas econômicas, vale fazer uma ressalva sobre um importante ponto de ruptura de Keynes com Moore, por meio de uma rejeição da dicotomia mooreana entre ações e fins. Keynes foi claramente um homem de ação pública. As crenças não bastavam por si, era necessário tomar ações efetivas, intervindo no curso natural dos fatos macroeconômicos, sendo que tais ações deveriam ser feitas a partir e por meio da esfera pública. 
a mesma economia que Clark lhe ensinou quando foi seu professor. Nos seus escritos pré-marginalistas, quando Veblen era seu aluno, Clark desenvolveu o que pode ser chamada de uma abordagem antropológica da economia. Então, o autor argumenta que os interesses de Veblen e Clark eram muito paralelos para serem frutos do acaso e aponta para a influência de Clark sobre Veblen em três frentes, quais sejam: a antropologia, a análise do consumo e a natureza da competição.

Em um de seus primeiros artigos, Clark teria argumentado que o homem que a teoria clássica pressupunha era muito mecânico e egoísta para corresponder à realidade. Os homens, segundo a abordagem de Clark, possuiriam desejos superiores, referentes à ciência, à ética e à estética. E eram essas demandas superiores que os economistas ignoravam. Se tal homem se tornasse mais rico sem se tornar mais culto, ele desejaria apenas um aumento quantitativo da gratificação do tipo social mais baixo. Na sua obra Filosofia da Riqueza, datada de 1886, Clark explicou o consumo exibicionista como a corrupção das demandas mais elevadas. Assim, a principal preocupação de Clark era com o efeito que o desejo pela estima tinha sobre as motivações ideais da natureza humana: a questão da estima poderia compensar o desenvolvimento dos desejos ditos mais elevados. Ainda de acordo com Stabile, Veblen aprofundou ainda mais essa idéia de consumo exibicionista, o que desembocou na sua concepção de consumo conspícuo.

Wesley Mitchell, um dos representantes do velho institucionalismo e discípulo de Veblen, argumenta que Veblen formou uma maneira muito peculiar de encarar a sociedade por ele ter vivido sua infância em uma situação consideravelmente diferente da cultura moderna. Por conta disso, Veblen era bastante impressionado pela diferença entre a vida que sua família vivia e a vida dita moderna: o contraste entre a vida dedicada a "fazer coisas úteis" e a vida de "fazer dinheiro". 12 Nessa última forma de vida, Veblen considerava tarefa difícil identificar as atividades em que os homens de negócios poderiam contribuir para a satisfação das necessidades humanas, o que o chocava de maneira considerável. Segundo Mitchell, essa visão de estranhamento deu a Veblen uma grande vantagem para o trabalho científico:

\section{"He gets one set of conventions impressed deeply upon him in the bome and then he goes into the world be finds strange. He has the advantage}

12 Stabile (1997) argumenta que Clark encarava como erradas as práticas envolvidas em fazer dinheiro por meio de barganhas desleais. Sob essas circunstâncias, a maior parte do processo de barganha não seria nada mais do que um refinamento da fraude. Essa patologia sugerida por Clark estaria associada, portanto, apenas a práticas tidas como ilegais. Eventualmente, especularíamos nós, esse questionamento de Clark teria sido estendido por Veblen, que associou as patologias a qualquer prática estritamente pecuniária. Uma importante pista dessa eventual extensão possivelmente estaria na tese de doutorado de Veblen, defendida na Universidade Yale, intitulada Ethical grounds of a doctrine of retribution, na qual poderiam ser encontrados possíveis indícios mais concretos dessa influência adicional de Clark sobre Veblen. Porém, essa tese, que teve Clark como orientador, está desaparecida da biblioteca daquela universidade desde 1935, como apontam Edgell e Tilman (1989, p. 1007). 


\section{of looking at things, which people who are to the manor born take as a matter of course, as strange novelties; and the result is that he is in a position to ask fundamental simple questions." (1969, p. 619).}

Essa forma diversa de ver o mundo levou Veblen a fazer questionamentos profundos acerca da natureza humana. Prova dessa busca é a sua Teoria da Classe Ociosa, da qual retiramos importantes inferências a respeito das origens das relações patológicas que os homens estabelecem com a riqueza, particularmente em sua forma monetária. Assim, no presente item abordaremos as principais idéias antropológico-evolucionárias de Veblen, o que nos auxiliará na busca por inferências mais concretas acerca de uma possível mudança de mentalidade que possa vir a ocorrer no desenvolvimento de nossa sociedade, aquela aventada por Keynes em relação ao amor pelo dinheiro.

\subsection{Acerca de Thorstein Bunde Veblen}

Almeida (1983), apresentando a Teoria da Classe Ociosa, aponta que o velho institucionalismo ganhou vida em um momento de transição do capitalismo americano, com o surgimento das grandes empresas oligopólicas, tanto na produção quanto no sistema financeiro. O desenvolvimento das grandes cidades, o surgimento dos grandes empreendimentos industriais, a construção das ferrovias, o nascimento das corporações como forma empresarial dominante, transformaram a velha sociedade e revolucionaram a distribuição de prestígio e poder no seu interior: essa era a época em que os grandes Barões Ladrões iniciaram seus grandes impérios.

Ainda segundo Almeida (1983), a obra de Veblen tentou fixar o sentido dessas transformações e analisá-las criticamente. Ela constituiu uma tentativa de entender o que Veblen chamou a "nossa cultura pecuniária", a partir da rejeição dos postulados e conclusões da teoria econômica convencional. Segundo Veblen, a partir do momento em que um teórico pretende explicar o fenômeno específico da economia "moderna", sua linha de abordagem deve ser feita necessariamente sob o ponto de vista do homem de negócios.

Veblen também concedia grande importância à análise do comportamento coletivo e das transformações operadas. Para ele, a mudança era sempre, em última instância, mudança nos hábitos de pensamento. A compreensão do funcionamento do sistema econômico dependia do reconhecimento de que as sociedades sofriam um processo evolutivo gradual, mas permanente, que transformava o contexto em que as instituições ganhavam existência e se consolidavam.

Mitchell (1969) aponta que Veblen pensava a humanidade como as espécies que tinham um tipo biológico definitivamente estabelecido milhões de anos atrás, ou seja, 
o corpo e a mente sempre estiveram ligados. A diferença intelectual entre o homem moderno e o homem arcaico não poderia ser atribuída a alguma melhora no cérebro dos humanos, e sim a um acúmulo de experiências, um crescimento lento e cumulativo da visão sobre a natureza e do conhecimento de como aplicar cada visão para a promoção dos interesses das espécies humanas. Os homens atingiram certas formas de utilizar o mundo ao seu redor a fim de satisfazer as suas necessidades: é um problema de evolução da cultura. Nas palavras de Mitchell, "[I]t is the economist primarily who is concerned with carrying on the tale of human evolution, because it is a question of the evolution of mind; and the way in which mind evolves, on Veblen's lines, is controlled primarily by what men do." (1969, p. 603). Ainda segundo ele, disso se infere que o fator no progresso humano mais suscetível de mudança e de desenvolvimento é o crescimento das instituiçõoes.

O homem adquire hábitos de pensamento inconscientemente, ou seja, os tipos de pensamento que o homem adquire é moldado por suas atividades cotidianas. Isto quer dizer que a mente do homem moderno foi moldada primeiramente pelas exigências de sobrevivência ou, da mesma forma, foi moldada pelas atividades econômicas. A partir do momento em que os homens conseguem desenvolver idéias que não são primariamente derivadas do domínio econômico, é porque eles atingiram uma eficiência em relação à sobrevivência.

Veblen pretendia contar a narrativa de como a acumulação gradual de pequenas mudanças nos hábitos humanos de pensamento era responsável por todos os alcances da humanidade. Mitchell sugere que sua abordagem conduz naturalmente para a questão de como é o longo processo de evolução que continuará no futuro, quais mudanças ocorrerão e em que tipo de sociedade elas implicarão. E infere que, se Veblen estiver correto, o mundo em que nossos netos crescerão será extremamente diferente daquele ao qual pertencemos.

\subsection{A Origem e a Função Social da Classe Ociosa}

No capítulo introdutório de $A$ Teoria da Classe Ociosa, cuja primeira edição é de 1899 , Veblen sugere que o surgimento de uma classe ociosa data da transição de um modo de vida pacífico para um mais predatório. As condições necessárias para o surgimento de tal classe são: (l) a comunidade deve ter um modo de vida predatório - a guerra ou a caça de grandes animais ou as duas, isto é, os homens, que nesses casos constituem a classe ociosa em potencial, devem estar habituados a infligir dano físico pela força ou por estratagema; (2) a subsistência deve ser possível de modo suficientemente fácil para que uma parte considerável da comunidade fique livre da rotina regular do trabalho. (1983, p. 8). 
Na comunidade industrial moderna a distinção entre funções dignas e indignas permanece refletida no preconceito em relação às ocupações servis. O conceito de dignidade, valia ou honra, é de importância fundamental no desenvolvimento das classes e de suas diferenças, como bem ressalta Veblen. O homem é um agente que em cada ato procura a realização de um fim concreto, objetivo e tem preferência por atividade eficaz e repugnância por esforço fútil. Tal atitude ou propensão pode ser denominada de instinto de artesanato: "O individuo ganba estima e evita censura tornando bem evidente a sua eficiência. O resultado é que o instinto de artesanato produz demonstração competitiva de força." (1983, p. 11)

Veblen sugere que onde quer que se encontre a instituição da propriedade privada, o processo econômico adquire o caráter de uma luta pela posse de bens. Em relação aos membros da comunidade que se ocupam com a acumulação de riqueza, dado que a instituição da propriedade privada não guarda relação com o mínimo de subsistência, o incentivo dominante para acumulação dessas classes sempre foi a distinção valorativa ligada à riqueza, ou seja, o primeiro dos motivos que leva a acumular riqueza é a emulação pecuniária.

Com o crescimento da indústria, a posse da riqueza se converte na prova mais facilmente demonstrável de um grau honroso de êxito, ou seja, torna-se a base convencional de estima e reputação. Nas palavras de Veblen,

\section{"A propriedade se torna, portanto, a base convencional da estima social. Nenbuma posição honrosa na comunidade é possivel sem ela. Torna-se in- dispensável adquirir e acumular propriedade a fim de conservar o próprio bom nome... Os bens materiais, sejam eles adquiridos agressivamente por esforço próprio, sejam eles adquiridos passivamente por berança de outros, tornam-se a base convencional da honorabilidade." (1983, p. 18).}

Poder-se-ia esperar que o efeito imediato da luta pecuniária seria o de tornar os homens laboriosos e frugais, se não interviessem outras forças econômicas ou outros elementos do processo de emulação. Entretanto, como sugere Veblen, "[c]ertos traços do processo de emulação...intervêm, circunscrevendo e modificando substancialmente a emulação, levando-a a outras direçôes tanto entre as classes pecuniariamente inferiores como na classe superior." (1983, p. 21).

Segundo Veblen, a mais forte das demandas secundárias da emulação é a abstenção do trabalho produtivo. Para obter e conservar a admiração dos outros, não basta ter riqueza e poder, é preciso mostrá-los de maneira clara. A desnecessidade de trabalhar não é apenas sinal de honra e mérito, é um requisito de decência e é, portanto, a marca convencional de posição social. Em suas próprias palavras, 
"Desde o tempo dos filósofos gregos até hoje, reconheceram os homens ponderados, com requisito de uma vida digna, bela ou mesmo virtuosa, que é preciso ter um certo ócio e estar livre de contato com certos processos industriais ligados às necessidades cotidianas da vida humana. A vida ociosa, por si mesma e em suas consequiências, é linda e nobre aos olhos de todos os homens civilizados.” (1983, p. 22).

Veblen argumenta que as instituiçóes, como são o produto de processos passados, nunca estão de pleno acordo com as exigências do presente, sendo, portanto, um elemento conservador, um fator de conservantismo. Um passo rumo ao desenvolvimento por si só constitui uma mudança de situação a exigir uma nova adaptação; torna-se, com efeito, um ponto de partida para um novo passo rumo ao ajustamento, e assim por diante, interminavelmente.

A liberdade e a facilidade de ajustamento dependem, em grande extensão, do grau de exposição dos membros individuais da coletividade às forças constrangedoras do ambiente. Se qualquer parcela da sociedade está protegida contra essa ação ambiental, estará presente uma tendência retardatária do processo de transformação social, sendo esta a situação da classe ociosa abastada, constituindo, portanto, a classe conservadora. Seu papel consiste em retardar o movimento de transformação e conservar o que é obsoleto. Vale adicionar que, segundo Veblen, as forças que levam ao reajustamento das instituições são, quase em sua totalidade, forças econômicas. Como ressalta em uma passagem,

"[A] pressão exercida pelo ambiente sobre o grupo, favorecendo o reajustamento do esquema de vida, colide com os membros do grupo, na forma de exigências pecuniárias; e é devido a esse fato - o de forças externas serem em grande parte reduzidas à forma de exigências pecuniárias ou econômicas - que nos é licito dizer que as forças que contam na direção de um reajustamento das instituiçôes em qualquer moderna comunidade industrial são principalmente forças econômicas; ou mais especificamente, essas forças assumem a forma de pressão pecuniária.” (1983, p. 90).

De acordo com Veblen, o exemplo normativo da classe ociosa age no sentido de aumentar a resistência das demais classes contra a inovação. Como o código da educação das convenções e dos usos tem mais ou menos o mesmo caráter de um todo orgânico, qualquer mudança considerável em um ponto do esquema influencia alguma mudança em outros pontos, senão uma reorganização geral. Assim, a repugnância a qualquer inovação equivale ao recuo diante de um esquema de vida estranho, ou é a aversão ao incômodo de precisar fazer o reajustamento exigido por qualquer mudança. Sobre essa questão, Veblen enfatiza que: 
"A atitude caracteristica da classe [ociosa] pode resumir-se na seguinte máxima: "Aquilo que é está certo"; enquanto a lei da seleção natural, em sua aplicação às instituiçôes humanas, resulta no sentido axioma; "Aquilo que é está errado"... "Certo" e "errado" são naturalmente empregados aqui sem qualquer significação sobre aquilo que deve ou não deve ser. Simplesmente se empregam no ponto de vista evolucionário (moralmente incolor) e são destinados a designar a compatibilidade ou a incompatibilidade com o processo evolucionário efetivo." (1983, p. 95).

Veblen observa de maneira curiosa que os muito pobres, e as pessoas cujas energias são absorvidas na luta pela subsistência, são conservadores, pois não podem realizar 0 esforço de pensar no futuro. Presume-se então que a instituição da classe ociosa atua no sentido de tornar conservadoras as classes mais baixas, retirando-lhes tanto quanto possível os meios de subsistência. A relação da classe ociosa com o processo econômico é uma relação pecuniária - relação de aquisição, não de produção; de exploração, não de utilidade. ${ }^{13} \mathrm{O}$ interesse dessa classe consiste em desviar o que puderem para seu próprio uso e reter o que tiverem na mão. Nas palavras de Veblen,

"A instituição de uma classe ociosa impede de imediato o desenvolvimento cultural: 1- mediante a inércia da própria classe, 2- mediante o exemplo normativo do dispêndio conspicuo e mediante o conservadorismo, e 3indiretamente, mediante o sistema de distribuição desigual da riqueza $e$ do sustento na qual a própria instituição repousa...Acrescente-se a isto que a classe ociosa tem também um interesse material em deixar as coisas como estão." (1983, p. 94).

\subsection{O Conflito de Interesses: Industrial vs Pecuniário}

De acordo com Foster e Ranson (1987), o que é fundamental na abordagem de Veblen é a distinção entre dois tipos de comportamento humano, um dito comportamento tecnológico, industrial ou instrumental, e o outro definido como cerimonioso, pecuniário ou de negócios, sendo que o último predomina sobre o primeiro no processo produtivo. O comportamento tecnológico, industrial ou instrumental é o tipo necessário à sobrevivência humana e é dinâmico e progressivo, porque muda conforme o estoque de conhecimento científico e tecnológico avança. Por sua vez, o comportamento cerimonioso, pecuniário ou de negócios caracteriza-se por elementos de poder ou controle sobre os outros indivíduos e, contrariamente ao primeiro, é inerentemente estático e regressivo, pois aqueles que possuem um alto status procuram manter seus privilégios.

13 Utilidade no sentido concreto de ter serventia. 
A evolução social é um processo de adaptação seletiva de temperamento e hábitos mentais, o que constitui o desenvolvimento das instituiçóes. Mas, paralelamente a esse desenvolvimento, ocorreu uma mudança mais substancial: mudanças correlatas à natureza humana. Nas palavras de Veblen,

"Em qualquer fase conbecida da cultura, diferente ou mais recente do que a fase inicial aqui tratada, os dons da boa indole, equiidade e simpatia indiscriminadas não favorecem apreciavelmente a vida do individuo (...) Ser livre de escrúpulos, simpatia, honestidade e consideração pela vida alheia podem favorecer, em um limite razoavelmente amplo, o bom êxito do individuo pertencente à cultura pecuniária." (1983, p. 101).

Para Veblen (1983), apesar dos interesses coletivos se concentrarem na eficiência industrial, o interesse imediato do indivíduo no regime emulativo é mais bem atendido por um comércio arguto e um trato inescrupuloso, o que leva o indivíduo a procurar o ganho mediante vias diretas e indiretas da indústria. No regime de emulação, os indivíduos de uma comunidade são rivais, e cada um será superior ao outro à medida que, sem escrúpulos, ele ultrapasse e prejudique o outro quando the convier.

Veblen ainda enfatiza que, no que diz respeito aos indivíduos ocupados diretamente com a técnica e com as operações manuais de produção, a ação educativa e seletiva atua para adaptar seus hábitos mentais a propósitos não-emulativos da vida coletiva. Assim, a ação educativa da vida econômica não é uniforme em todas as suas manifestações, pecuniária ou industrial. Portanto, relativamente à conservação seletiva de capacidades e atitudes individuais, podem ser distinguidas duas linhas, a pecuniária e a industrial, sendo que o indivíduo se inclina relativamente mais ou menos por uma ou pela outra.

Mas, de acordo com Veblen (1983), o chamado "homem econômico" seria inútil para os propósitos da indústria moderna, pois essa exige um interesse impessoal e não emulativo no trabalho a se realizar. Entretanto, o autor alerta para o fato de que, mesmo nas ocupações industriais, a eliminação seletiva dos traços pecuniários é um processo incerto, pois, como a posição normativa da classe ociosa impôs sobre as classes inferiores muitos traços da teoria de vida da classe ociosa, indiretamente conservou os traços pecuniários no corpo da população.

Em The Theory of Business Enterprise, cuja primeira edição data de 1904, Veblen aponta que o homem de negócios se tornou uma força controladora na indústria, pois mediante o mecanismo do investimento e do mercado controlou as fábricas e os processos, sendo que estes estabelecem o ritmo e determinam a direção para o restante da economia. $\mathrm{O}$ autor ressalta ainda que nenhum dos processos de uma indústria 
mecânica é auto-suficiente. Cada processo precede ou procede outro processo numa seqüência que não tem fim, e esse processo industrial abrangente forma um complexo de subprocessos fragilmente equilibrado. Qualquer mau ajuste do sistema envolve uma perda maior do que simplesmente a desabilitação de um ou dois membros da complexa estrutura industrial. Assim, a manutenção do equilíbrio desse abrangente processo industrial tornou-se um problema da mais grave urgência a partir do advento da indústria mecânica. Por conseguinte, segundo Veblen, a administração das várias plantas e processos industriais é um trabalho de grande conseqüência para o "well being" da comunidade.

Segundo Veblen (1965), como os interesses pecuniários dos homens de negócios não são necessariamente melhor satisfeitos por uma constante manutenção do equilíbrio industrial, surge um conflito de interesses dos homens de negócios, que possuem somente interesse pecuniário, e da comunidade, pois os distúrbios do sistema são de interesse dos homens de negócios na medida em que deles emergem seus ganhos.

Ao se perguntar até quando essa situação de conflito perduraria, Veblen afirma que as pessoas que estão continuamente engajadas no ambiente de negócios virão a ter padrões para julgar o que é certo muito diferentes dos padrões daqueles que estão engajados no processo mecânico - produtivo. Os indivíduos com ocupação pecuniária estão sempre inclinados a pensar sobre os seus direitos, principalmente sobre o direito de propriedade. Por outro lado, aqueles que realizam trabalho industrial viriam a pensar as coisas não em termos dos direitos naturais, mas em termos de causa e efeito. Veblen afirma que essas pessoas não mais entenderiam as doutrinas de direito natural, porque elas teriam adentrado a uma estrutura mental pela qual não mais poderiam compreendê-las, ao menos que lhes mostrassem que há uma causa material por trás disso.

Veblen aponta para a instabilidade das bases institucionais da empresa de negócios - o sistema de direitos naturais. As instituições e pontos sob o esquema de direitos naturais lhe pareciam ser de caráter essencialmente temporário. O sistema de liberdade natural era produto de um regime pacífico de artesanato e pequeno comércio, mas o sistema industrial estaria quebrando a estrutura dos direitos naturais ao torná-los fúteis. Nas palavras do autor, "[I]t seems possible to say this much, that the full dominion of business enterprise is necessarily a transitory dominion. It stands to lose in the end the one or the other of the two divergent cultural tendencies wins, because it is incompatible with the ascendancy of either." (1965, p. 400).

Em The common man and the vested interests, de 1919, Veblen argumenta que sob a ordem em que os negócios controlam a indústria, a população dos países civilizados se divide em duas classes principais: aqueles que possuem riqueza investida em grandes 
holdings e que, por conseguinte, controlam as condições de vida do restante, e aqueles que não têm riqueza suficiente em grandes holdings e que, portanto, são controlados pelos outros. Assim, o que diferencia uma classe de outra é ter ou não riqueza suficiente para influenciar o funcionamento do sistema. ${ }^{14} \mathrm{E}$ vale lembrar que não se trata de um processo inerentemente definitivo, pois o nível de riqueza necessário para assegurar a independência cresce com o passar do tempo. Mas, segundo o autor, a mais importante conseqüência que decorre dessa diferenciação diz respeito à divisão entre o homem comum e os interesses escusos. Nas palavras do autor,

"It is a division between those who control the conditions of work and the rate and volume of output and to whom the net output of industry goes as free income, on the one hand, and those others who have the work to do and to whom a livelihood is allowed by these persons in control, on other band." (1965, p. 161).

Veblen define o interesse escuso como um direito legítimo de ter "algo" proveniente de "nada", sendo que a mais comum indicação da renda livre são os ativos intangíveis. Os possuidores desse direito são chamados de kept classes, contrastados com aqueles que não possuem esse direito, os homens comuns, sendo que os primeiros são menos numerosos e menos "úteis" para a comunidade. Como enfatiza Veblen,

"To take their own part, therefore, the vested interests and the kept classes
have nothing more perplexing to do then simply to follow the leadings
of their settled code in all questions of law and order and thereby to fall
neatly in with the leading of their own pecuniary advantage, and always
and on both counts to keep their poise as safe and sound citizens intelli-
gently abiding by the good old principles of right and honest living which
safeguard their vested interests." (1919, p. 176-7).

Mas o fato de vir do "nada" não significa que os interesses escusos não custam nada, muito pelo contrário. Segundo o autor os custos podem ser consideravelmente altos quando se leva em conta o custo para a comunidade. Os interesses escusos são riqueza imaterial, ativos intangíveis, não um crescimento do equipamento tangível ou dos recursos materiais.

Quanto ao uso dessa renda livre ${ }^{15}$ que se forma nas mãos das kept classes, Veblen sugere que é utilizada para o consumo de supérfluos. Mas, segundo o autor, o sentimento

14 Em relação aos bens de capital, a sua propriedade cria vantagens diferenciadoras entre os indivíduos de uma comunidade. Para Veblen, a falta de acesso ao capital impede trabalhadores hábeis de participar do processo produtivo, enquanto que o controle do capital permite que pessoas não hábeis reivindiquem uma renda.

15 Ou seja, possivelmente a renda que sobra depois do consumo não conspícuo. 
de incongruência e desutilidade em relação a essas leis e costumes - o direito natural - que prevaleciam no século XVIII tende a aumentar, ou seja, uma quebra de sentimento entre os interesses escusos e os homens comuns. Assim, Veblen demonstra o natural decaimento da empresa de negócios.

\subsection{Indagaçôes Acerca do Pensamento Vebleniano}

Um dos primeiros questionamentos que podem surgir acerca da abordagem de Veblen diz respeito ao conflito existente entre os dois interesses fundamentais do homem, o pecuniário e o industrial. Conforme exposto nos subitens anteriores, esses dois interesses são inerentes à natureza humana, mas um pode ser predominante sobre o outro e, dependendo de quem predomina, as conseqüências para o processo produtivo e, assim, para o well being da sociedade, são diversas.

Na comunidade industrial moderna o interesse pecuniário claramente predomina sobre o industrial, o que leva essencialmente a uma não-utilização da total capacidade produtiva da sociedade, diminuindo o seu well being. Desse processo de incompatibilidade entre os interesses coletivos - industriais - e os interesses individuais - pecuniários - decorre uma importante inferência feita por Veblen: o natural decaimento da empresa de negócios, pois os homens ligados ao processo industrial produtivo não mais compartilhariam dos valores da classe pecuniária, principalmente no que diz respeito ao direito de propriedade. Além disso, como mostrado no subitem acerca da classe ociosa, o próprio desenvolvimento institucional permitido pela classe ociosa a fim de, principalmente, aumentar a garantia do direito de propriedade, teria como conseqüência a própria superfluidade da classe pecuniária na condução do processo industrial. Já antecipando uma especulação feita a seguir: em que medida essa presumida superfluidade corroboraria a mudança de mentalidade antevista por Keynes, conforme detalhado ao final do item 1.2?

Mas, como se daria, segundo o próprio Veblen, essa mudança? A princípio, pode-se deduzir que a motivação pecuniária deixaria de ser protagonista, dando vez ao domínio do motivo industrial, por meio de uma mudança institucional provocada pela incompatibilidade das instituições existentes com os interesses da sociedade. Como o próprio Veblen ressalta, as instituições são produto do passado, incompatíveis com os interesses presentes, e daí decorre o caráter evolutivo aberto e infinito da vida econômica e social. E essa evolução se dá exatamente nas instituições, ou nos hábitos de pensamento.

Entretanto, o que garantiria que, posteriormente, não voltasse a haver o domínio do interesse pecuniário? Veblen atribui aos engenheiros a maior capacidade de conduzir 
o processo industrial da maneira mais satisfatória para o well being da comunidade. No entanto, Veblen não explica por que esses engenheiros, ao assumirem o papel dos velhos capitães da indústria, necessariamente conduziriam o processo de maneira distinta da dos homens de negócios. Provavelmente, mais uma vez a explicação cairia na questão da evolução das instituições. Mas o problema que surge dessa abordagem decorre exatamente de não se poder inferir, com certeza, para onde um processo evolutivo necessariamente conduz, embora seja possível detectar algumas de suas tendências potenciais.

Contudo, apesar dessas dúvidas que se originam da abordagem de Veblen, as suas idéias evolucionárias nos fornecem interessantes pistas acerca dos futuros possíveis de nossos netos. 'Possíveis' porque, em se tratando de um ambiente de caráter incerto e sugestóes evolucionárias, não podemos fazer mais do que inferências acerca do futuro, as quais serão apresentadas no próximo item.

\section{CONSIDERAÇÕES FINAIS: OS FUTUROS POSSÍVEIS DE NOSSOS NETOS}

Tomando como base as inferências de Keynes e Veblen, sugerimos neste item respostas tentativas às perguntas legadas por Keynes: como e por que ocorrerá a desejada mudança de valores, o que fará com que as pessoas encarem o dinheiro como ele realmente é - vale dizer, uma patologia - e se voltem para o que realmente importa, que é exercer a verdadeira arte de viver? Ou, reformulando a pergunta para o que mais interessa para os presentes dias, e utilizando os termos de Veblen, como e por que o interesse produtivo superará o interesse pecuniário?

Como apresentado na primeira parte deste artigo, a intuição de Keynes é bastante otimista no que diz respeito à natureza humana. Retomando os ideais do jovem Keynes do grupo de Bloomsbury, o velho Keynes continua se mostrando confiante quanto à constante evolução moral dos homens, como se ele refletisse na natureza humana em geral aquilo que parecia ser uma característica peculiar sua: um equilíbrio entre a razão instrumental e a razão emocional.

Quanto a Veblen, por sua abordagem ser essencialmente antropológico-evolucionária, não podemos atribuir-lhe o mesmo otimismo presente em Keynes, embora Veblen também aponte como tendência natural o decaimento do interesse pecuniário e a conseqüente submissão deste ao interesse produtivo. E, contrariamente à abordagem de Keynes, as inferências de Veblen são mais do que intuições: elas têm um embasamento antropológico-evolucionário bastante coerente e consistente. 
Mas, tomando como ponto de partida o nosso presente, podemos realmente nos mostrar tão otimistas quanto ao futuro de nossos netos? A grande verdade é que o chamado capital financeiro tem encontrado formas cada vez mais eficazes de se reciclar e de se multiplicar, deixando o interesse produtivo de lado. Por conta disso, a mudança de mentalidade prevista por Keynes parece bastante improvável e a inferência vebleniana do decaimento natural da empresa de negócios bastante irrealista. Que tipo de mudança é então necessária para que a intuição de Keynes e que a tendência apresentada por Veblen realmente se realizem? Keynes destaca uma mudança moral, Veblen aponta para uma mudança institucional, sendo que uma não necessariamente exclui a outra, ou, melhor dizendo, uma não ocorre sem a outra. Ou seja, para que o interesse pecuniário seja deixado em segundo plano, deve ocorrer uma verdadeira transformação de valores, tanto no que diz respeito às relações pessoais quanto impessoais, que mudará o foco do bem-estar individual para o bem-estar coletivo, relembrando a idéia de unidade orgânica de Moore e de Keynes. Esta seria a transformação pelo lado positivo, a tal transformação de mentalidade sugerida por Keynes.

Mas, e se acontecesse algo próximo ao que Veblen preconizou, ou seja, um desgaste entre os valores que fundaram o predomínio do interesse pecuniário e a grande maioria da sociedade não envolvida pelo predomínio desse interesse, os chamados "trabalhadores"? Assim, o que se pretende sugerir aqui é que a mudança provavelmente não viria de uma maneira aparentemente "espontânea", como apontada por Keynes, pela qual as pessoas "naturalmente" passariam a encarar o mundo de outras formas, dando valor ao que realmente importa na vida. Em verdade, essa falta de clareza quanto à maneira pela qual se daria tal mudança sugerida por Keynes nos remete novamente a Moore, mais especificamente à sua religião, pela qual mais importavam os fins, ou seja, o "como" se dá a mudança não é algo crucial. Portanto, pretendemos sugerir que a mudança tenderia a vir pelo próprio desgaste dos valores - o meio pelo qual se daria a mudança - que sustentam o interesse pecuniário, como sugere Veblen, o que exigiria mudanças institucionais profundas.

\section{REFEREANCIAS BIBLIOGRÁFICAS}

Albin, Peter S. Barriers and bounds to rationality: essays on economic complexity and dynamics in interactive systems. With an Introduction by Duncan K. Foley. Princeton: Princeton University Press, 1988.

Almeida, M. H. T. Apresentação de Thorstein Veblen (1899) A teoria da classe ociosa. Coleção "Os Economistas”. São Paulo: Abril Cultural, 1983.

Bridel, P.; Presley, J. John Maynard Keynes and the French connection. The Manchester School, v. LXV, n. 4, p. 452-465, Sept. 1997. 
Carabelli, A. The methodology of the critique of the classical theory: Keynes on organic interdependence. In: Bateman, Bradley W.; Davis, John B. (eds.), Keynes and philosophy. Edward Elgar, 1991.

Cardoso, F; Lima, G. T. A visão de Keynes do sistema econômico como um todo orgânico complexo, Anais Eletrônicos do XXXIII Encontro Nacional de Economia (Anpec), Natal, Dezembro 2005.

Davis, J. B. Keynes's view of economics as a moral science. In: Bateman, Bradley W.; Davis, Jonh B. (eds.), Keynes and philosophy. Edward Elgar,1991a.

. Keynes's critiques of Moore: philosophical foundations of Keynes's economics. Cambridge Journal of Economics, v. 15, p. 61-77, 1991b.

Dequech, D. Uncertainty: individuals, institutions and technology. Cambridge Journal of Economics, v. 28, n. 3, p. 365-378, 2004.

Edgell, S.; Tilman, R. The intellectual antecedents of Thorstein Veblen: a reappraisal. Journal of Economic Issues, v. XXIII, n. 4, Dec. 1989.

Fitzgibbons, A. Keynes's vision. Oxford University Press, 1988.

Foster, G. P.; Ranson, B. Thorstein Veblen on money and production. Economies et Sociètes, Tome XXI, n. 9, Sept. 1987.

Gribbin, J. Deep simplicity: bringing order to chaos and complexity. London: Random House, 2005.

Hutton, A. Institutionalism: old and new. In: O’Hara, P. (ed.), Encyclopedia of political economy, V. I. London: Routledge, 1999.

Keynes, J. M. [1926)]. O fim do 'laissez-faire'. In: Szmrecsányi, Tamás (org.), John Maynard Keynes. Editora Ática, 1984.

. [1930]. The economic possibilities for our grandchildren. In: Szmrecsányi, Tamás (org.), John Maynard Keynes. Editora Ática, 1984.

. [1930]. A treatise on money. In: Moggridge, D. (ed.), The collected writings of John Maynard Keynes. V. VI. London: Macmillan, 1971.

. [1931]. Essays in persuasion. In: Moggridge, D. (ed.), The collected writings ofJohn Maynard Keynes. V. IX. London: Macmillan, 1972.

. [1933]. Alfred Marshall. In: Moggridge, D. (ed.), The collected writings of John Maynard Keynes. V. X. London: Macmillan, 1972.

. [1937]. A teoria geral do emprego. In: Szmrecsányi, Tamás (org.), Jobn Maynard Keynes. Editora Ática, 1984.

. [1938]. My early beliefs. In: Moggridge, D. (ed.), The collected writings of John Maynard Keynes. V. X. London: Macmillan, 1972.

. The general theory and after. Parte II: Defense and development. In: Moggridge, D. (ed.), The collected writings of John Maynard Keynes. V. XIV. London: Macmillan, 1973. 
Lima, G. T. Em busca do tempo perdido: a recuperação pós-keynesiana da economia do emprego de Keynes. Rio de Janeiro: BNDES, 1992.

Mini, P. Keynes, Bloomsbury and the general theory. Basingstoke: Macmillan, 1991.

Mitchell, W. C. Types of economic theory: from mercantilism to institutionalism. New York: Kelley, 1969.

O’Donnell, R. M. Keynes: philosophy, economics \& politics. London: Macmillan, 1989.

Preston, R. H. The ethical legacy of John Maynard Keynes. In Reese, David A. (org.), The legacy of Keynes. San Francisco: Harper \& Row, 1987.

Stabile, D. The intellectual antecedents of Thorstein Veblen: a case for John Bates Clark. Journal of Economic issues, v. 31, n. 3, p. 817-825, Sept. 1997.

Skidelsky, R. Jobn Maynard Keynes - The economist as saviour 1920-1937. New York: The Penguin Press, 1992.

Veblen, T. B. [1899]. A teoria da classe ociosa. Coleção "Os Economistas". São Paulo: Abril Cultural, 1983. . [1904]. The theory of business enterprise. New York: Kelley, 1965.

. [1919]. The vested interests and the common men: modern point of view and the new order. New York: Kelley, 1919.

Winslow, E. G. Keynes and Freud: psychoanalysis and Keynes's account of the 'animal spirits' of capitalism. Social Research, v. 53, n. 4, 1986. 